\title{
Interseccionalidade lésbica? \\ O apelo pelo desmonte de opressões ${ }^{1}$
}

\author{
BLAUDT, Vanessa Lima² \\ CAETANO, Marcio ${ }^{3}$ \\ RANGEL, Mary ${ }^{4}$
}

\section{RESUMO}

Com o objetivo de aprofundar as reflexões concernentes às opressões vivenciadas por lésbicas em território latino-americano, este artigo destrincha algumas particularidades do movimento lésbico-feminista considerando-o uma ação política, cujo desígnio é o de aniquilar distintos eixos opressores - entre tantos, o racismo, o classismo, o heterossexismo - que agem juntos. Apelos em favor de incorporar a pluralidade de diferenciações humanas e as desigualdades que se originam dessas diferenças tocam em uma ação fundamental para movimentos visionários, a de promover visibilidades.

Lésbicas. Opressões. Interseccionalidade.

\section{Lesbian intersectionality? The call for the dismantling of oppression}

\begin{abstract}
In order to deepen the reflections concerning the oppression to which lesbians are undergone in Latin America, this article examines some particularities of the lesbian feminist movement, which is considered a political action, whose objective is to annihilate different oppressive strands - racism, classism, heterosexism, among others - that act jointly. Appeals for incorporating the plurality of human differentiations and the inequality that is due to theses differences lead to a fundamental action for visionary movements, which is promoting visibilities.
\end{abstract}

Lesbians. Oppressions. Intersectionality.

\footnotetext{
${ }^{1}$ Este trabalho é dedicado a duas lideranças lésbicas, Marisa Fernandes e Yone Lindgren.

2 Doutoranda e Mestra em Educação pelo Programa de Pós-graduação da Universidade Federal Fluminense (UFF). E-mail: valb.edfisica@gmail.com. Lattes: http://lattes.cnpq.br/2294239994224036. ORCID: https://orcid.org/0000-0002-3917-5399. 3 Doutor em Educação pela UFF, Professor no Instituto de Educação da Universidade Federal do Rio Grande - FURG, Brasil. E-mail: mrvcaetano@gmail.com. Latttes: http://lattes.cnpq.br/2262480943131351. ORCID: http://orcid.org/0000-0002-4128-8229. ${ }_{4}^{4}$ Doutora em Educação. Professora da Universidade Federal Fluminense e da Universidade do Estado do Rio de Janeiro. E-mail: mary.rangel@lasalle.org.br. Lattes: http://lattes.cnpq.br/2173146648220598. ORCID: https://orcid.org/0000-0003-3834-942X.
}

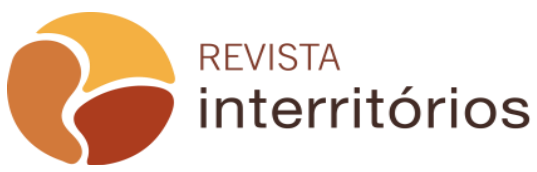
Caruaru, BRASIL | V.6 N.10 [2020] 


\section{Interseccionalidad lésbica? El llamado al desmantelamiento de la opresión}

\section{RESUMEN}

Para profundizar las reflexiones sobre la opresión experimentada por las lesbianas en el territorio latinoamericano, este artículo revela algunas particularidades del movimiento feminista lésbico considerándolo una acción política, cuyo objetivo es aniquilar diferentes ejes opresivos, entre muchos, el racismo, clasismo, heterosexismo, que actúan juntos. Los llamamientos a favor de incorporar la pluralidad de las diferenciaciones humanas y las desigualdades que surgen de estas diferencias se refieren a una acción fundamental para los movimientos visionarios, la de promover la visibilidad.

Lesbianas. Opresiones. Interseccionalidad.

\section{Intersezionalità lesbica? L'appello allo smantellamento dell'oppressione}

\section{SINTESE}

Al fine di approfondire le riflessioni sull'oppressione subita dalle lesbiche nel territorio latinoamericano, questo articolo svela alcune particolarità del movimento lesbico-femminista considerandolo un'azione politica, il cui scopo è quello di annientare diversi assi oppressivi - tra i tanti, il razzismo, classismo, eterosessismo - che agiscono insieme. Gli appelli a favore dell'incorporazione della pluralità di differenziazioni umane e delle disuguaglianze che derivano da queste differenze toccano un'azione fondamentale per i movimenti visionari, quella di promuovere la visibilità.

Lesbiche. Oppressioni. Intersezionalità.

\section{INTRODUÇÃO}

"Em uma sociedade em que o bom é definido em relação ao lucro, e não a necessidades humanas, deve sempre existir um grupo de pessoas que, mediante a opressão sistemática, pode ser levado a se sentir dispensável, ocupando o lugar do inferior desumanizado. Nessa sociedade, esse grupo é formado por pessoas negras e 
do Terceiro Mundo, pela classe trabalhadora, pelos idosos e pelas mulheres.

AUDRE LORDE

Neste ensaio, nosso interesse é destrinchar algumas particularidades do movimento lésbico-feminista, considerando-o uma ação política, cujo desígnio é o de aniquilar eixos opressores que se interligam ou se interseccionam - entre tantos, o racismo, o classismo, o capacitismo, o heterossexismo -, produzindo opressões a partir das diferenças humanas. Procuramos, dessa maneira, fomentar uma reflexão crítica no que tange a orientações focalizadas no entrelaçamento de diferentes desigualdades sociais, motivadas por também diferentes pertencimentos ou marcadores identitários - como gênero, raça, classe, sexualidade, apenas para exemplificar. A reivindicação de movimentos visionários em favor de incorporar a pluralidade de diferenças humanas e as desigualdades que se originam dessa característica tão inerente aos seres humanos, nos embates e teorizações atuais, almeja uma ação fundamental, a de promover visibilidades. Notadamente, dentro dos estudos alusivos às lesbianidades, essa importante perspectiva de atitude vem, desde o final da década de 1970, ganhando contornos volumosos.

O entrecruzamento de desigualdades sociais correlacionadas a gênero, raça e classe foi, de maneira conveniente, evidenciado em um manifesto de teóricas feministas, lésbicas e negras denominado The Combahee River Collective Statement, na década de 1977. Nesses escritos, o entrelaçamento dos sistemas opressores vigentes, o racismo, o sexismo, o heterossexismo e 0 classismo, constrangendo demasiadamente as mulheres de cor, fazia-se presente, e rechaçava um incômodo universalismo feminista. A fragmentação das desigualdades foi, então, publicizada e rejeitada, assim como o separatismo lésbico - cuja análise se confinava sob a dominância do determinismo sexual e biológico somente, e a concomitância de opressões e desigualdades, enfim, abraçada.

Se, já nesse tempo citado, existiam vozes atentas a opressões entrançadas sofridas por determinados grupos sociais, 0 termo interseccionalidade, conhecido hoje por teorizar a interligação de dois ou mais marcadores identitários e as opressões oriundas desse encontro, foi somente inaugurado e sistematizado em 1989, por Kimberlé Crenshaw (1991), teórica feminista estadunidense. Para ela, 0 ato de intersecionar as discriminações de gênero, classe e raça tem o poder de promover avanços concernentes aos direitos humanos. Também nos anos 1980, a intersecção entre as injustiças sociais, oportunizadas por opressões racistas e sexistas, foi proposta por Angela Davis, em seu texto Women, race and class (1981), e por Bell Hooks, em seu 
livro intitulado Ain't I a woman? Black women and feminism (1981). As feministas, em palavras concisas, contrapõem-se à homogeneização das experiências das mulheres e fazem um apelo em favor do reconhecimento da raça e do racismo tanto no interior dos múltiplos espaços das sociedades quanto dentro do próprio movimento feminista, de cor branca e elitista. Bell Hooks (2019, p. 93) deixa o testemunho de uma caminhada transformadora no movimento feminista:

[...] por anos testemunhei a relutância de pensadoras feministas brancas em reconhecer a importância de raça. Testemunhei sua recusa em abrir mão da supremacia branca, sua falta de vontade de reconhecer que um movimento feminista antirracista era a única base para tornar real a sororidade. E testemunhei a revolução de consciência que aconteceu quando mulheres individuais começaram a se libertar da negação, a se libertar do pensamento de supremacia branca. Essas maravilhosas mudanças restauram minha fé no movimento feminista e fortalecem minha solidariedade a mulheres.

Dito isso, na intenção de dialogar, em especial, com as lesbianidades, apresentamos algumas vozes do feminismo lésbico contemporâneo que põem no enfoque de suas análises a identidade política lésbica e os atravessamentos necessários nela de categorias como a política heterossexual, a raça e a classe. Tendo em mente a necessidade de olhar as injustiças sociais, que aqui se fazem particularmente presentes, visibilizando-as, as contribuições de autoras principalmente de um feminismo lésbico, atentas às opressões materiais interseccionadas de mulheres e lésbicas, são de uma utilidade ímpar para que seja possível redefinir lutas e agendas políticas condizentes com a realidade.

Assim, na seção sequente, os diálogos apreendidos de teorizações lésbico-feministas dedicam-se sobremaneira a arquitetar ferramentas teóricas e práticas hábeis a desmantelar as opressões materiais interligadas experimentadas por lésbicas. Ao tentarem romper com o modelo idôneo da heterossexual e serem imediatamente definidas por tal diferença desumanizadora, essas mulheres, junto as suas vivências, são constrangidas e marginalizadas. Para contextualizar este debate, é preciso evidenciar que o entrecruzamento de experiências lésbicas toca em um ponto importante: a invisibilidade. Isso porque, se as primeiras reivindicações de uma perspectiva nitidamente lésbica, na década de 1970, originaram-se por intermédio de mulheres brancas e de classe média, a ausência de considerações afinadas às diferenciações de raça e classe impulsionaram novos apelos.

\section{O entrecruzamento de desigualdades sociais promovendo visualidades}


O início da autonomia organizacional e teórica lesbiana principiou enfrentamentos próprios, por se empenharem em um diagnóstico faltoso ao movimento feminista nos anos 1970: a supremacia heterossexual. Yuderkys Espinosa Miñoso (2016), feminista comprometida com as questões lésbicas e raciais, sublinha que, se antes a heterossexualidade era um espaço desprovido de reflexões no feminismo, mais contemporaneamente o elo entre esse movimento e os estudos das lesbianidades se faz presente. Há, ela diz, no interior da teoria feminista, uma compreensão cada vez mais íntegra da heterossexualidade obrigatória como um sistema social produtor do sujeito mulher, cujos desejos e identidade assegurem a plena dependência do homem.

As primeiras reivindicações de uma perspectiva nitidamente feminista lésbica, nos anos 1970, criticaram o movimento feminista por suas análises pouco ou nada atenciosas à regulação heterossexual na vida das mulheres. Criando caminhos próprios, mas influenciadas pelos movimentos e agitações sociais, as feministas lésbicas começaram então a denunciar o efeito controlador das supremacias heterossexual e masculina. Elas apresentaram novas análises, cujo principal conteúdo era questionar abertamente as perspectivas naturalistas consensuais sobre a diferença dos sexos, fomentada pela sociedade heterossexual. A heterossexualidade é desacomodada, assim como a ideia inocente de que é ela uma prática sexual natural de atração entre dois sexos opostos. A estrutura heterossexual básica é enfim notada como instituição ou regime político, que se apoia incansavelmente nas categorias invariáveis, dicotômicas e naturalizadas de sexo e/ou gênero.

Em seu texto Heterossexualidade compulsória e existência lésbica, publicado originalmente em 1980, Adrienne Rich deixa notório o caráter político da heterossexualidade, afirmando ser a heterossexualidade compulsória uma instituição política que subordina as mulheres ao poder masculino. Consoante o entendimento de Rich (2010), a obrigatoriedade heterossexual associa-se às formas de produção capitalista, que sentenciam a divisão sexual do trabalho e impulsionam os muitos antagonismos entre homens e mulheres. Nesse ponto, a diferença dos sexos aparece dando sentido e justificando as posições (consideradas inatas) das mulheres, que são destinadas ininterruptamente aos homens e, assim, por exemplo, ao trabalho doméstico. Dessa maneira, as mulheres, que são circunscritas apenas aos homens e por eles apropriadas, permanecem reféns do que ela nominou de heterocentrismo. Nesse aprisionamento, encontram-se o casamento e a orientação sexual, ambos direcionados também, de maneira inevitável, a eles.

Nessa imposição institucionalizada, Rich (2010) aponta ainda a posição invisibilizada das lésbicas, que assim devem se manter para que posições e 
comportamentos próprios de mulheres heterossexuais sobrevivam. Quaisquer atos que fujam dos limites sexuais masculinos impostos são mantidos submersos, esclarece Rich (2010). Em razão dessa condição degradante, a alternativa conceitual e política de as lésbicas se afugentarem é encontrada nos conceitos de existência lésbica e continuum lésbico. O primeiro significa um ato de resistência e uma recusa a um modelo compulsório de vida que se nutre do direito masculino ao acesso irrestrito às mulheres. O continuum lésbico, por sua vez, ilustra a preocupação de Rich (2010) com a destituição das lésbicas de suas próprias histórias e memórias, e tem a serventia de resgatar o transcurso das histórias de vida de cada mulher e as experiências múltiplas de identificação da mulher, não apenas as sexuais-genitais.

Monique Wittig, nos anos 1970, iniciou também os seus escritos sobre a heterossexualidade obrigatória como um regime político, que se apoia nas relações entre as classes naturalizadas de homens e mulheres. Para ela, a obrigatoriedade de relação social entre o homem e a mulher é, de fato, um mecanismo potente de subordinação e opressão. Wittig (2006) afirma ser a heterossexualidade não uma mera prática sexual, mas absolutamente uma ideologia, denominada pensamento straight (hétero), que oprime e cala principalmente as lésbicas, as mulheres e os homens homossexuais, ou 0 diferente/outro.

Rich (2010) e Wittig (2006), a partir de suas críticas à ordem impositiva da heterossexualidade, abrem caminho para um pensamento lésbico cujas bases se apoiam sobretudo em afastar a lesbianidade do campo limitado das práticas sexuais, dispondo-a em um campo político e social, capaz de promover ações que abrangem as lutas contra a opressão de mulheres, independente da orientação do desejo sexual. Como bem argumenta Norma Mogrovejo (2000), nesse tempo, a relação entre as mulheres passou a ser tratada não mais como simplesmente uma prática ou preferência sexual, mas como uma possibilidade de nomear social, política e publicamente uma identidade coletiva.

Ampliando de forma significativa a discussão, mais contemporaneamente, Jules Falquet (2006) traz em seus escritos a denúncia da invisibilidade lésbica no interior do próprio movimento social feminista. A negligência à representação das experiências de lésbicas "de cor" impulsionou alguns embates, intencionados a construir identidades e ações políticas no contexto da América Latina. Eles acusaram o movimento lésbico de ser racista e classista já no fim dos anos 1970. Nele, apenas as mulheres brancas e anglo-saxônicas tinham voz (FALQUET, 2006). As lésbicas negras, então, foram (e vêm) ganhando maior visibilidade e afirmando sua existência. Diante disso, novas perspectivas vêm sendo construídas para que sejam consideradas as histórias das mulheres em muitos lugares e tempos. 
Retrocedendo rapidamente ao passado, o entrelaçamento de diferentes formas de injustiças sociais atravessou, de forma original, as argumentações de Audre Lorde (1934-1992), feminista norte-americana e poeta lésbica negra, conforme a escritora se define. Suas contribuições muito enriquecem este debate porque visibilizaram, já na década de 1980, as vivências de lésbicas negras e a trama de opressões sofridas. Em sua obra Irmã outsider ${ }^{5}$, Lorde (2019) contrapõe-se às crenças na superioridade de determinada classe, raça, idade e sexo; todas caminham sem piedade por marcadores identitários que traduzem as diferenças, intrínsecas a todos nós, seres humanos. O embaraço, argumenta ela, não está nas diferenças, mas na maneira como aprendemos a tratá-las durante a vida. E as tratamos de forma absolutamente desigual, ignorando-as, destruindo-as, subalternizando-as. Diante de tal cenário desanimador, segundo ela, a renúncia institucionalizada da diferença é uma obrigação imperiosa, que tem o escopo de fazer cessar o descarte desenfreado de pessoas. Nesse sentido, a autora vislumbra o racismo, o machismo, 0 elitismo, o etarismo, a heteronormatividade e a homofobia como formas de cegueira humana, ou como a nossa incapacidade de (re)conhecer 0 enriquecimento humano a partir de suas diferenças (LORDE, 2019, p. 90).

Lorde (2019) debruça-se sobre as vivências de lésbicas negras sustentando serem elas posicionadas, no interior da própria comunidade negra, na mira do racismo e machismo. Há, ela diz, uma histeria em oposição às lésbicas. Essas mulheres e a ausência de uma relação de subserviência com um homem negro trazem incômodos e fazem emergir ameaças: para que essas mulheres conquistem o respeito, a amizade e o apoio de homens negros, é necessário unir-se a ele e evitar, assim, corromper-se com uma vida cuja prioridade é outra mulher. As intimidações relatadas têm a mestria de subjugar o sexo (desumanizado) feminino e ratificar, como de costume, a superioridade do homem. Nos termos de Lorde (2019, p. 96), deixamos a mensagem de homens negros para as mulheres negras: "eu sou o único prêmio que vale a pena ganhar [...]. Então, se você me quer, é melhor se colocar no seu lugar, que é longe das outras; do contrário, vou te chamar de lésbica e acabar contigo".

Se às lésbicas negras, segundo Lorde (2019), impõem-se reprimendas no que toca à relação entre pessoas do mesmo sexo, tal censura não se confirma quando existem relações entre homens. Nesse cenário, onde impera 0 machismo e o heterossexismo, a crença secular na superioridade masculina e heterossexual, há a mantença da também secular inferioridade e subalternização da mulher diante de um homem. Dele, ela precisa. Famílias consideradas despadronizadas, porque chefiadas por mulheres, são uma

\footnotetext{
${ }^{5}$ A primeira edição dessa obra foi publicada no ano de 1984, nos Estados Unidos, porém apenas em 2019 foi publicada no Brasil. 
ameaça a padrões tão bem definidos. Para a autora, o enclausuramento e a dependência naturais direcionados apenas às mulheres condenam a possibilidade engrandecedora de ambos os sexos caminharem unidos, em busca de espaços de lutas cujas causas promotoras de transformações sociais sejam as mesmas.

Presentemente, na esteira de uma proposta atenta ao entrelaçamento de opressões, o debate sobre o entrecruzamento de diferenças alcança as proposituras de Ochy Curiel (2013). As críticas à arquitetada superioridade do homem, junto às lutas engendradas contra o heterocentrismo e o paradigma patriarcal, explica a feminista, têm sido aparatos bastante utilizados pelos diversos rumos do feminismo, porque facultam desacomodar a secular naturalização de homens e mulheres. Outrossim, tais discordâncias apresentadas foram impulsionadoras do nascimento de uma perspectiva feminista nitidamente lésbica nos anos 1970, cujas protagonistas, que eram brancas, de classe média, americanas ou europeias, promoveram reflexões inéditas, deixando um lugar até então silencioso. A autora amplia as problematizações lésbicas afirmando que, se num primeiro momento de emersão, o movimento e seus pleitos ganharam visualidades, num segundo momento o que se viu foi a continuada apreensão das questões lésbicas se dar de forma linearmente eurocêntrica, sem imbricações necessárias com os sistemas de dominação classista ou racista, ou mesmo atenta às especificidades do nominado terceiro mundo. Como bem aponta Lorde (2019), constitui-se em um ato de desrespeito qualquer reflexão feminista cujo teor distancie as mulheres negras, pobres, lésbicas e as do terceiro mundo.

Os argumentos da feminista Bell Hooks (2019, p. 73) são aqui pertinentes porque defendem que "a única esperança genuína de libertação feminista está numa visão de mudança social que desafia o elitismo". O patriarcado, explica ela, hegemonicamente de cor branca, subordina as mulheres habitantes do terceiro mundo. Esse fato impulsiona a proliferação de diferenças vultuosas entre ricos dominantes e pobres, a classe trabalhadora, e acentua sobremaneira a "feminização da pobreza". O feminismo e as mulheres que o compõem têm a incumbência de incluir em suas teorizações e práticas instrumentos que reorientem seus olhares para os oprimidos. No entanto, sublinha ela, a maioria das mulheres do chamado primeiro mundo, principalmente as brancas, não descolonizou o pensamento no que concerne ao racismo, elitismo e sexismo.

O feminismo, para Curiel (2013), precisa instituir-se tanto como uma vasta teoria política, que concebe produções e pensamentos múltiplos com o escopo de analisar sistemas de opressão, quanto como uma ética filosófica, questionadora de normas patriarcais e heterocêntricas, que intenta descortinar caminhos isentos das opressões sociais. No interior de tais perspectivas, ela tem 
construído uma crítica convincente ao regime da heterossexualidade e às opressões interseccionadas de sexo, classe e raça, que são reiteradas pelo mundo dominante capitalista. Para além disso, a autora dialoga com o feminismo decolonial, fazendo uma crítica à ausência de grupos sociais oprimidos e excluídos, como as mulheres e os grupos étnicos e racializados, isto é, todos os que não têm privilégios de classe, raça, sexo e sexualidade, das produções de conhecimento e construções históricas.

Ademais, Curiel, em entrevista concedida a Teixeira, Silva e Figueiredo (2017), atenciosa às intrincadas opressões vivenciadas por lésbicas, contrapõese à ideia de que exista interseccionalidade do ponto de vista lésbico, porque tal teorização poderia uniformizar todo o movimento, marcado por tantas outras diferenças que singularizam as mulheres. Para ela, o imprescindível é existirem pontos de vistas coadunados aos projetos políticos almejados, e um dos mais essenciais é a abolição de opressões desumanas, que facultam incansável e naturalmente a objetificação de seres humanos, fazendo brotar as desigualdades sociais. Então, afirma ela, a interseccionalidade é precária porque, de acordo com o próprio nome, ela intersecciona, isto é, promove o encontro de marcadores identitários que supostamente se constroem de maneira autônoma. Dessa forma, na singularidade de um indivíduo, acham-se, de um lado, a negra e, de outro lado, a mulher, e, em um determinado momento, após uma inicial separação, essas identidades se encontram, interseccionam-se. No entanto, tais identidades, como tantas outras, são, desde a sua gênese, produzidas por sistemas de opressão; conjuntura essa não enfrentada pela interseccionalidade, parte de uma proposta liberal. Frente a isso, é evidente, sustenta ela, que o:

[...] Estado Nacional Liberal não vai pensar as opressões, nem interessa a este que desapareçam as opressões que produzem as negras, como o racismo, as opressões que produzem a lésbica, o regime da heterossexualidade, nem as opressões que produzem as mulheres, o patriarcado. Por tudo isso, eu digo que a interseccionalidade é uma proposta completamente liberal. Eu nunca falo de interseccionalidade, porque não me interessa a inclusão e a diversidade que implicam um projeto liberal. Eu quero que acabemos com as opressões, não é isso? (TEIXEIRA; SILVA; FIGUEIREDO, 2017, p. 117).

As relações lésbicas construídas, observa Falquet (2006), precisam estar conectadas às situações materiais de opressão inerentes ao mundo neoliberal. Nele, os efeitos materiais de opressão são a precarização e o empobrecimento de mulheres e lésbicas, reforçados pelo mercado internacional de trabalho que hierarquiza de acordo com critérios de sexo, classe, raça e nacionalidade. Além disso, o neoliberalismo tenciona perpetuar um modelo neonuclear de família, que 
é o espaço no qual se cristalizam e reproduzem os sistemas patriarcais também desiguais. Essa família, apesar da conhecida diversidade de núcleos familiares, impõe o casal monogâmico, cujos integrantes são o casal jovem, heterossexual, branco, rico, belo e saudável. Todos esses atributos exigidos se unem a um potente traço religioso reacionário e, é claro, à figura naturalizada das mulheres, incumbidas da reprodução e das tarefas domésticas. Na família neonuclear, há a essencialização da heterossexualidade e das relações entre homens e mulheres, bem como a intensificação de binarismos e a decorrente desconsideração de outras formas de experienciar a vida.

Assim, apesar de admitir a importância das lutas feministas e lésbicas contra o caráter binário e natural da diferença dos sexos ou gêneros, Falquet (2012) avança em seu excelente trabalho teórico lésbico-feminista. Ela anuncia que as análises das opressões praticadas nas sociedades precisam apoderarse da heterossexualidade e considerá-la um sistema social e uma ideologia que cria e naturaliza da mesma forma tanto a diferença dos sexos quanto as diferenças de raça e classe. Assim, a autora vem construindo uma crítica a partir da inserção simultânea de sexo, raça e classe, com foco na globalização neoliberal e no seu importante sistema independente de opressão, a heterossexualidade. Falquet (2012) avança em seus comentários e considera a importância das lutas de cada sexualidade vivente $e$ dos gêneros marginalizados, todavia destaca que há uma inclinação difundida em investigar e fortificar, no interior do próprio movimento LGBTI6, a relação social "gaymasculinas-patriarcais brancas e de classe média", cujo enfoque recai quase sempre e tão somente sobre o sexo.

Nos dias atuais, as desigualdades imersas na globalização neoliberal reclamam ser improrrogável engrandecer a análise sobre as relações de sexo, raça e classe simultaneamente. Isso porque "o nacionalismo, a xenofobia e o essencialismo (de raça e de sexo) retornam em pleno vigor com a globalização e o desenvolvimento de um pensamento político reacionário, naturalista e ahistórico", amarrado sobremaneira ao fundamentalismo religioso (FALQUET, 2012, p. 23). Entretanto "não nos enganemos sobre o inimigo principal', pois, no mundo globalizado, o fundamento de processos ideológicos (como a naturalização das posições sociais dos indivíduos) "é certamente um processo material de exploração, de extração e de concentração de riquezas", argumenta Falquet (2012, p. 23).

As questões lésbicas precisam unir-se principalmente a análises que descortinem os sistemas de opressão que produzem as diferenças e identidades, pois é através desse movimento que são possíveis as formulações

${ }^{6}$ Lésbico, gay, bissexual, trans e intersexo. 
de estratégias para articulações políticas, capazes de enfrentar as opressões sofridas por grupos sociais considerados minoritários (CURIEL, 2013). A disseminação do conservadorismo e das religiões, o naturalismo entre homens e mulher, a cultura, as lutas de distintos movimentos sociais, tudo isso exige que lembremos da adequada base do lesbianismo feminista, que é a execução de um projeto político. Somente com ele é possível enfrentar um sistema-mundo nocivo aos nossos corpos e vida, que é o heterossexista patriarcal, racista e neoliberal.

Frente a tantos problemas, a proposta de Falquet (2012) é a de desacomodar e aperfeiçoar as relações e posições sociais interpeladas por sexo, raça e classe, que se desenham sob a constante vigilância do pensamento straight. Influenciada por um feminismo de base materialista, que desvelou a inexistência, nas bases de opressões, de uma natureza dada e a existência de justificativas e marcadores diversos que tomaram para si a própria designação natural, a teórica trilha rumos interessantes. Ela se desinteressa por uma política identitária reservada a problematizações que toquem apenas nas propriedades representativas, físicas ou mentais de um sexo, de uma raça ou de uma classe. As opressões e explorações que atravessam as muitas diferenças sociais, diz ela, têm de integrar o eixo de ação e combate do feminismo e de outros movimentos sociais. Só assim é possível perturbar e desmanchar as bases do pensamento dominante.

No Brasil, por sua vez, Fátima Lima (2018, p. 69), pensadora das questões principalmente de lésbicas racializadas, contrapõe-se ao "apagamento e silenciamento" da existência lésbica. Além disso, de acordo com suas proposições, as lésbicas negras experimentam, em seus corpos e em suas subjetividades, eixos múltiplos de opressão, quais sejam: raça, gênero e sexualidade. Todos esses marcam "uma tripla opressão que, ao ser coadunada com outros marcadores categoriais como classe, geração, território, entre outros, intensifica os processos de exclusão" (LIMA, 2018, p. 69).

Consoante os argumentos de Cláudia Regina Lahni e Daniela Auad (2018), pesquisadoras também brasileiras, sobre as mulheres lésbicas se debruçam, além da diferença hierarquizada (e, acrescento, naturalizada) dos sexos, cujo modelo proeminente é o masculino, as desigualdades imanentes da homossexualidade (desviante). As autoras vislumbram, então, eixos de opressão que atingem as lesbianidades.

Duplamente desviantes, porque não homem e não heterossexual, as mulheres lésbicas sofrem, na maior parte do tempo, dupla discriminação, específicas desigualdades e muita invisibilidade no que se refere aos aspectos que definem sua identidade sexual e de gênero. Nesse sentido, os processos de 
identificação e as políticas de reconhecimento são uma necessidade e urge a construção de múltiplos modelos. (AUAD; LAHNI, 2013, p. 157, grifo nosso).

De forma profícua, um movimento grandioso em benefício de direitos das mulheres, como bem aponta Bell Hooks (2019), atravessa sobremaneira a implementação de uma educação para a consciência crítica. Nesse ensinamento, as questões concernentes às mudanças sociais teriam enfoques mais abrangentes, isto é, estariam atentas às problematizações oriundas de um elitismo desenfreado, de um racismo segregador e de um sistema político cuja função é subordinar as mulheres aos homens, o heterossexual.

\section{Considerações finais}

Conforme evidenciado neste texto, uma proposta lésbico-feminista disposta a enfrentar o entrelaçamento de opressões que desmantelam a vida das mulheres precisa acoplar-se a cenários ainda pouco visitados. As desigualdades sociais de lésbicas negras, pobres e de classes trabalhadoras somente serão aniquiladas quando eixos dominantes do próprio movimento de mulheres enxergarem que todas essas singularidades e diferenças têm a serventia de marginalizar quem dentro dela(s) se encontra $(m)$.

Como recorda Falquet (2006), o lesbianismo é, de certa maneira, um movimento novo, influenciado por tendências múltiplas do feminismo, que transitam por diversos contextos e pensamentos. Por ora, as influências anotadas prendem-se à concepção das lesbianidades como uma posição política, uma proposta transformadora que luta por independência - nos tantos cotidianos público e privado de vida - das mulheres com relação aos homens. Tal assentimento vai muito além de ideias mais simplistas hipnotizadas por definições ou desconstruções identitárias. Significa entender que a obrigatoriedade da heterossexualidade, num mundo patriarcal e androcêntrico, não se constitui em um apenso para análises; diferentemente, é um eixo autônomo, que carrega consigo políticas variadas de explorações na vida de mulheres e lésbicas, e sobretudo na vida de mulheres e lésbicas pobres, negras, integrantes do nominado terceiro mundo.

A materialidade das práticas de opressão necessita estar no cerne das preocupações dessa proposta lésbico-feminista, isto é, as divisões sexual, racial e social do trabalho, que atingem sobretudo as mulheres "de cor" e aquelas insertas nos países de terceiro mundo, como sugerem as feministas que aqui dialogaram. Somente assim as lutas podem tornar-se verdadeiramente hábeis a fomentar progressos. 


\section{REFERÊNCIAS}

AUAD, Daniela; LAHNI, Cláudia Regina. Cidadania democrática e homossexualidades: comunicação no combate à violência contra as mulheres lésbicas. Emblemas, v. 10, n. 2, p. 147-166, jul./dez. 2013.

CRENSHAW, Kimberlé Williams. Mapping the margins: intersectionality, identity politics, and violence against women of color. Stanford Law Review, v. 43, n. 6, p. 1241-1299, 1991.

CURIEL, Ochy. La nación heterosexual: análisis del discurso jurídico y el régimen heterosexual desde la antropología de la dominación. Bogotá: Edición Brecha Lésbica y En La Frontera, 2013.

DAVIS, Angela. Women, race and class. New York: Random House, 1981.

FALQUET, Jules. De la cama a la calle: perspectivas teóricas lésbico-feministas. Bogotá: Brecha Lésbica, 2006.

FALQUET, Jules. Romper o tabu da heterossexualidade: contribuições da lesbianidade como movimento social e teoria política. Cadernos de Crítica Feminista, ano VI, n. 5, p. 8-31, dez. 2012.

HOOKS, Bell. Ain't I a woman?: black women and feminism. Cambridge: South End, 1981.

HOOKS, Bell. O feminismo é para todo mundo. Rio de Janeiro: Rosa dos Tempos, 2019.

LAHNI, Cláudia Regina; AUAD, Daniela. Feminismos e direito à comunicação:

lésbicas, bissexuais e transexuais em série. Laplage em Revista, Sorocaba, v. 4, n. 1, p. 92-108, jan./abr. 2018.

LIMA, Fátima. Corpos e processos de subjetivação em mulheres negras e lésbicas.

Cadernos de Gênero e Diversidade, v. 4, n. 2, abr./jun. 2018.

LORDE, Audre. Irmã outsider. Belo Horizonte: Autêntica, 2019.

MIÑOSO, Yuderkys Espinosa. Historizar las disputas, indagar las fuentes: hipótesis para pensar el movimiento de lesbianas en América Latina. Atlánticas - Revista Internacional de Estudios Feministas, v. 1, n. 1, p. 240-259, 2016.

MOGROVEJO, Norma. Un amor que se atrevió a decir su nombre: la lucha de las lesbianas y su relación con los movimientos homosexual y feminista em América Latina. México: Plaza y Valdes, 2000.

RICH, Adrienne. Heterossexualidade compulsória e existência lésbica. Bagoas, v. 4, n. 5, p. 17-44, 2010. 
TEIXEIRA, Analba Brazão; SILVA, Ariana Mara; FIGUEIREDO; Ângela. Um diálogo decolonial na colonial cidade de Cachoeira/BA: entrevista com Ochy Curiel. Cadernos de Gênero e Diversidade, v. 3, n. 4, out./dez. 2017.

WITTIG, Monique. El pensamiento heterosexual y otros ensayos. Madrid: Egales, 2006. 